\title{
Role of echocardiography in clinical hypertension
}

\author{
Jae-Hwan Lee and Jae-Hyeong Park
}

\begin{abstract}
Hypertension is a major and correctable cardiovascular riskfactor. The correct diagnosis of hypertension and precise assessment of cardiovascular risk are essential to give proper treatment in patients with hypertension. Although echocardiography is the second-line study in the evaluation of hypertensive patients, it gives many clues suggesting bad prognosis associated with hypertension, including increased left ventricular (LV) mass, decreased LV systolic function, impaired LV diastolic function, and increased left atrial size and decreased function. Along with conventional echocardiographic methods, tissue Doppler imaging, three-dimensional echocardiography, and strain echocardiography are newer echocardiographic modalities in the evaluation of hypertensive patients in the current echocardiographic laboratories. Understanding conventional and newer echocardiographic parameters is important in the diagnosis and assessment of cardiovascular risk in hypertensive patients.
\end{abstract}

Keywords: Hypertension, Cardiovascular risk, Echocardiography

\section{Introduction}

Cardiovascular diseases are major leading health problems in the world [1], and hypertension is a major risk factor for cardiovascular diseases and stroke which have significantly higher morbidity and mortality [2].

Although the echocardiographic examination is usually recommended as a second-line study in the evaluation of hypertensive patients, it is one of most commonly used imaging modality and has given insights into pathophysiology and clinical implications in patients with hypertension. It can detect anatomical and functional changes easily in a real-time, quick, and reproducible manner. Echocardiography is more sensitive for the detection of asymptomatic organ damage that can be used as a determinant of cardiovascular risk. So, it is important in the clinical management in selected hypertensive patients.

In this review, we want to describe the role of echocardiography in the evaluation of hypertensive patients.

\section{Review}

Recommendations of echocardiography in the current hypertension guidelines

In the $2013 \mathrm{ESH} / \mathrm{ESC}$ Guidelines for the management of arterial hypertension, echocardiography is the second-line

\footnotetext{
* Correspondence: jaehpark@cnu.ac.kr

Department of Cardiology in Internal Medicine, School of Medicine,

Chungnam National University Hospital, Chungnam National University, Daejeon, Korea
}

study based on medical history, physical examination, and findings from routine laboratory tests [3]. The guidelines recommended performing echocardiographic examination in patients who are suspected with having left ventricular hypertrophy (LVH), left atrial (LA) dilatation, or concomitant heart diseases (class IIb: usefulness/efficacy is less well established by evidence/opinion, level $\mathrm{C}$ : consensus of opinion of the experts and/or small studies, retrospective studies, and registries).

The 2014 Canadian Hypertension Education Program (CHEP) guidelines recommended the echocardiographic use in the selected patients [4]. Routine echocardiographic study is not recommended in all patients with hypertension (grade D: recommendations are based on expert opinion alone). However, the echocardiographic examination for the evaluation of $\mathrm{LVH}$ is useful in selected patients to define the future cardiovascular risk (grade C: recommendations are based on trials that have lower levels of internal validity and/or precision, trials reporting invalidated surrogate outcomes, or results from non-randomized observational studies). Echocardiographic evaluation of LV mass and systolic and diastolic LV function is recommended in patients with hypertension suspected to have LV dysfunction or coronary artery disease (grade D). LV ejection fraction (LVEF) should be assessed objectively by an echocardiogram or nuclear imaging in patients with hypertension and evidence of heart failure (grade D). 
The latest guideline of the Eighth Joint National Committee (JNC 8) did not mention about the use of echocardiography [5]. The previous guideline of JNC 7 discussed about the echocardiographic examination to detect $\mathrm{LVH}$ in the assessment of cardiovascular risk [6].

\section{Appropriateness of echocardiography in hypertension}

Because the echocardiography is the most common and the first-line imaging study in many clinical scenarios, appropriateness is an important issue in reducing the cost of inappropriate use of echocardiography. The American College of Cardiology Foundation published the appropriate use criteria for echocardiography in cooperation with the American Society of Echocardiography and along with key specialty and subspecialty societies [7]. They have analyzed many clinical scenarios and categorized three groups according to the appropriate use score: appropriate (median 7-9), uncertain (median 4-6), and inappropriate (median 1-3).

The use of echocardiography as an initial evaluation of suspected hypertensive heart disease is appropriate (appropriate use score 8). Also, echocardiography is appropriate in patients with prior test result that is concerning for heart disease or structural abnormality (appropriate use score 9). Initial evaluation of known or suspected heart failure (HF), systolic or diastolic, based on symptoms, signs, or abnormal test results, is appropriate (appropriate use score 9). Re-evaluation of known HF with a change in clinical status or cardiac examination without a clear precipitating change in medication or diet is appropriate (appropriate use score 8).

However, routine evaluation of systemic hypertension without symptoms or signs of hypertensive heart disease is inappropriate (appropriate use score 3). Initial echocardiographic evaluation of ventricular function with no symptoms or signs of cardiovascular disease is inappropriate (appropriate use score 2). It is also inappropriate for the evaluation of LV function with prior ventricular function evaluation showing normal function in patients in whom there has been no change in clinical status or cardiac examination (appropriate use score 1). However, re-evaluation of known hypertensive heart disease without a change in clinical status or cardiac examination is uncertain (appropriate use score 4). The usual recommendations of echocardiographic examination in the evaluation of arterial hypertension are summarized in Table 1, and simplified algorithm of the echocardiography is summarized in Figure 1.

\section{Echocardiographic evaluations}

\section{Left ventricular mass and geometry}

The evaluation of LVH with measuring mass and geometry is the major role of echocardiography in hypertensive patients. In the detection of $\mathrm{LVH}$, echocardiographic assessment is more sensitive than electrocardiography $[8,9]$. Echocardiography is a good diagnostic tool in the determination of overall cardiovascular risk and helps in the selection of appropriate antihypertensive therapy [9].

The calculation of LV mass is based on subtraction of the LV cavity volume from the volume enclosed by the LV epicardial surface. To measure proper LV mass, precise evaluation of thicknesses of the interventricular septum and LV posterior wall in addition to the dimension of the interventricular cavity is needed. The LV mass has been measured using this equation that has been recommended by the American Society of Echocardiography (ASE) which is derived from two-dimensional linear LV measurements [10];

$$
\begin{aligned}
& \text { Left ventricular mass }(\text { gram }) \\
& \quad=0.8 \times 1.04 \\
& \quad \times\left[(\text { LVIDd }+ \text { PWTd }+ \text { SWTd })^{3}-\text { LVIDd }^{3}\right]+0.6
\end{aligned}
$$

where LVIDd is the LV internal dimension at end diastole, PWTd is the LV posterior wall thickness at end diastole, and SWTd is interventricular septal wall thickness at end diastole. Although this ASE-recommended formula showed excellent correlation with necropsy study $(r=0.90, p<0.001)$ [11], even small errors in the measurement are magnified and lead to big differences [10].

The relative wall thickness (RWT) is calculated by the formula $(2 \times$ PWTd)/LVIDd [10]. RWT can categorize the LVH as either concentric (RWT greater than 0.42 ) or eccentric (RWT less than 0.42). With certain cutoff values for $\mathrm{LV}$ mass have been widely accepted for the presence of LVH $\left(125 \mathrm{~g} / \mathrm{m}^{2}\right.$ for men and $110 \mathrm{~g} / \mathrm{m}^{2}$ for women), patients with hypertension can be classified into four subgroups (Figure 2) [10,12]. LV geometric pattern provides additional prognostic information in hypertensive patients. Concentric hypertrophy is associated with increased cardiovascular events after adjustment for other cardiovascular risk factors including LV mass [13]. Also, concentric hypertrophy showed the greatest mortality risk in patients suspected with coronary artery disease [14].

Three-dimensional echocardiography has been introduced to assess LV mass (Figure 3A) [15,16]. Because Mmode and two-dimensional echocardiographic techniques have many limitations, three-dimensional echocardiography provides more precise measurements theoretically. Realtime three-dimensional echocardiographic measurement of LV mass showed an excellent correlation $(r=0.95, p<$ 0.001 ) with measurement by magnetic resonance imaging [16]. Real-time three-dimensional measurement showed better degree of agreement than M-mode or twodimensional calculation of LV mass. Also, inter- and intraobserver variability were lower in the real-time threedimensional echocardiographic method. Because of these 
Table 1 Clinical situations when the echocardiography is recommended in the evaluation and treatment of arterial hypertension

\begin{tabular}{ll}
\hline Clinical situations & Signs \\
\hline Heart failure is suspected & -Symptoms: exertional dyspnea, orthopnea, generalized edema, etc. \\
& -Abnormal physical examination: cardiac murmurs, pretibial pitting edema, etc. \\
& -Abnormal ECG results: left ventricular hypertrophy, left atrial enlargement, left bundle branch block, pathologic Q \\
& waves, poor R progression, atrial fibrillation etc. \\
& -Abnormal chest X-ray findings: cardiomegaly, pulmonary edema, pleural effusion, etc. \\
& -Symptoms: exertional dyspnea, orthopnea, etc. \\
Structural heart disease is & -Abnormal physical examination: cardiac murmurs, pretibial pitting edema, etc. \\
suspected & -Abnormal ECG results: left ventricular hypertrophy, right ventricular hypertrophy, left atrial enlargement, right atrial \\
& enlargement, etc. \\
& -Abnormal chest X-ray findings: cardiomegaly, pulmonary edema, pleural effusion, etc. \\
Ischemic heart disease is & -Symptoms: typical chest pain, exertional dyspnea, etc. \\
suspected & -Abnormal ECG results: significant ST changes, pathologic Q wave, etc. \\
Refining cardiovascular risk &
\end{tabular}

advantages over conventional two-dimensional echocardiography, three-dimensional echocardiographic measurement can be a technique of choice in the studies of the regression of $\mathrm{LVH}$ with antihypertensive medications.

\section{Left ventricular systolic function}

Rapid and reliable assessment of LV systolic function is another advantage of the echocardiography. Although coronary artery disease is the most common cause of LV systolic dysfunction, arterial hypertension is a possible cause of functional impairment of the LV. Echocardiography can give information about the possibility of coronary artery disease in addition to calculation of LV function.

Several echocardiographic indices have been introduced to estimate LV systolic function. Among them, LVEF is the most used and the most practical systolic index that has been used as a prognostic factor in various cardiovascular

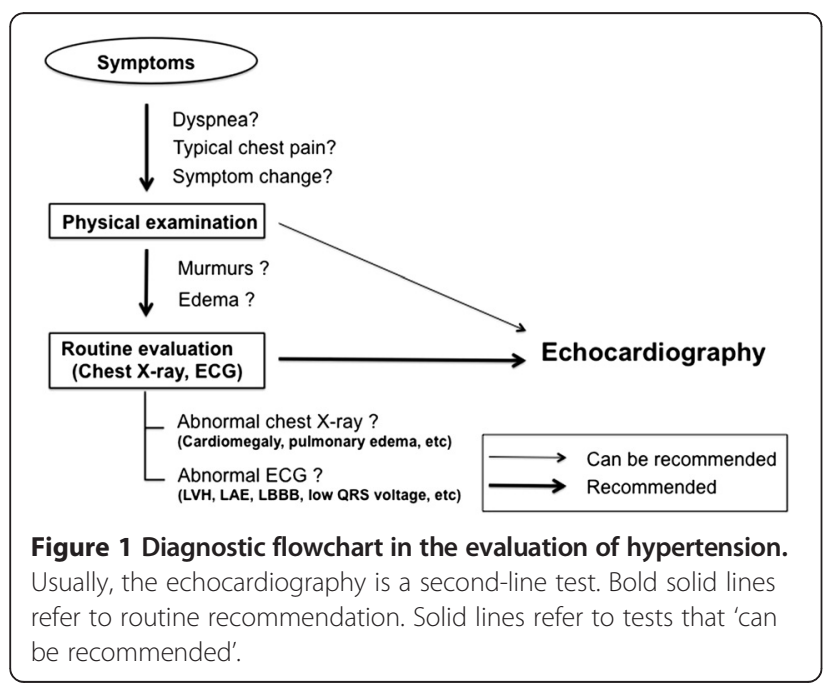

diseases [16,17]. It can be calculated from the ratio between the volume ejected during systole over the enddiastolic volume of the LV. Echocardiographic measurement of ejection fraction is usually done using modified Simpson's method (Figure 4) [10,18]. A normal LVEF is more than $55 \%$ in adults [10].

Three-dimensional echocardiographic measurements of LV volumes have been available with technical improvement (Figure 3B) [19-21]. Three-dimensional measurement does not require the assumption that the LV is a prolate ellipse, and it can measure LV volumes as it is. So, three-dimensional echocardiographic measurement has advantages over the calculation of LV volumes in patients with regional wall motion abnormalities or LV aneurysms.

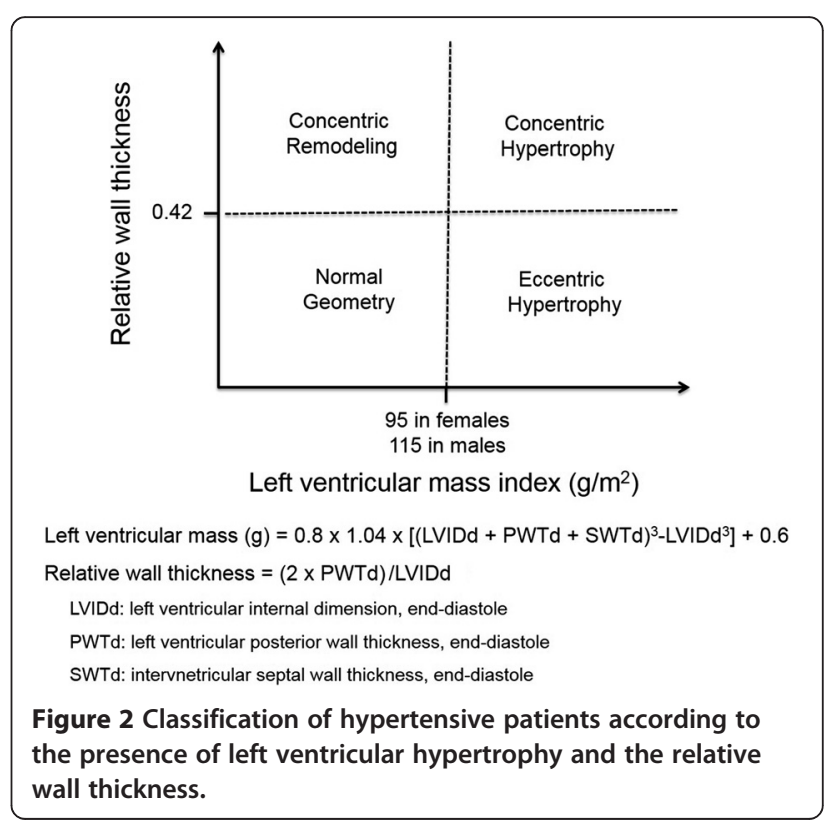



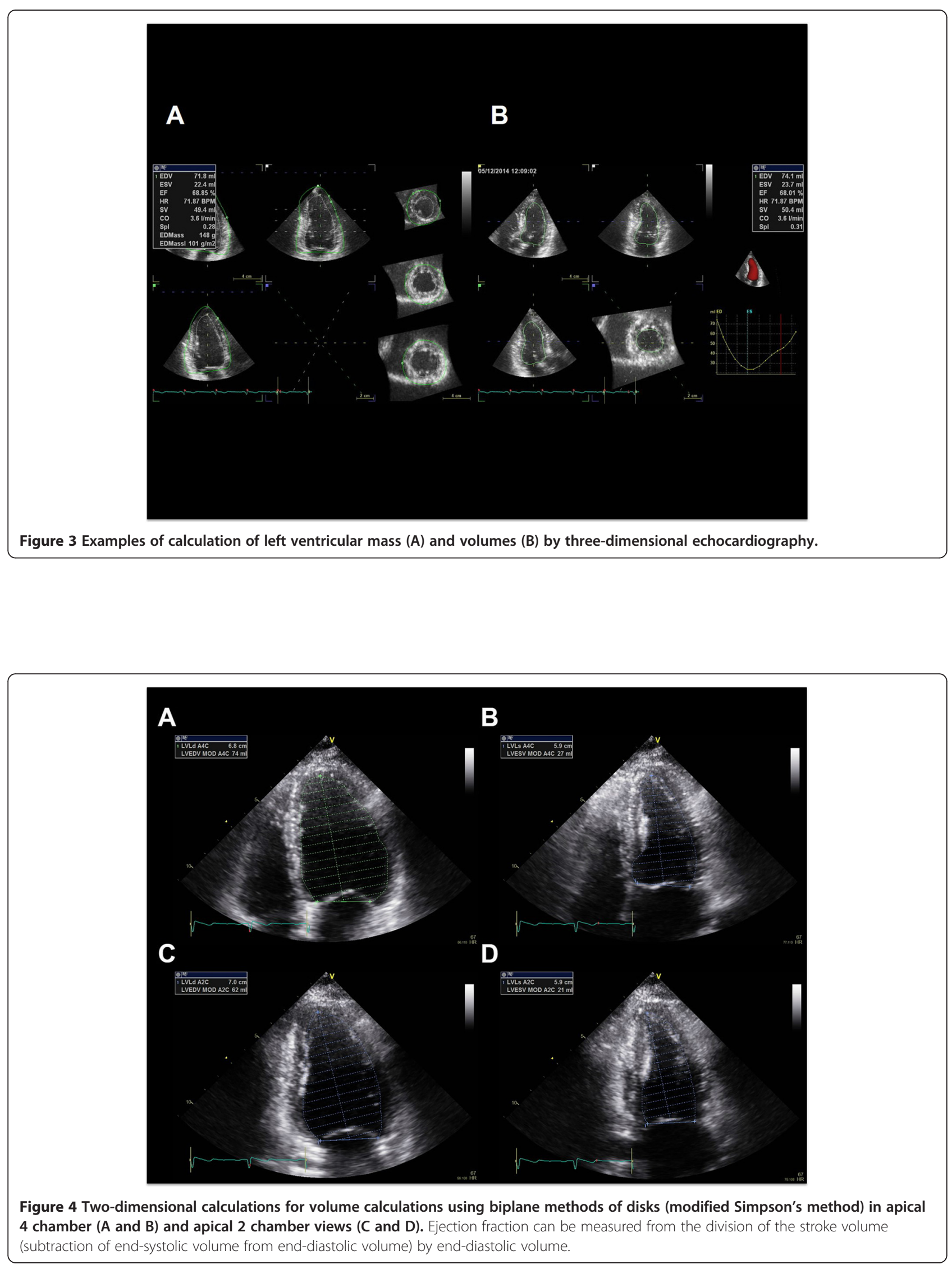
Three-dimensional echocardiographic measurements have been shown high degree of agreement with the measurements by cardiac magnetic resonance imaging [22-24]. Moreover, these studies demonstrated significant increases in reproducibility over conventional two-dimensional echocardiographic measurements.

Because impairment of LV long-axis function occurs at the early stages in many cardiac diseases, its assessment provides a very useful index in the evaluation of hypertensive patients [25]. The LV longitudinal function can be assessed with atrioventricular plane displacement that was abnormal in hypertensive patients without overt systolic dysfunction [26].

Tissue Doppler imaging is the new echocardiographic modality to measure mitral annular movement. Mitral annular velocity was decreased in hypertensive patients with normal ejection fraction [27], and it can be used to detect subclinical LV systolic dysfunction [28]. Measurements of myocardial function by strain echocardiography are newer indices that have advantages over other conventional echocardiographic measurements like LVEF. Strain can measure global and regional myocardial function, objectively. Two-dimensional speckle-tracking echocardiography analyzes myocardial deformation by tracking of natural acoustic markers that are generated from the interactions between ultrasound and myocardium. These natural acoustic markers are referred to as speckles $[29,30]$. Although there are several echocardiographic algorithms tracking the speckles, they are able to get angle-independent and multi-directional (longitudinal, radial, and circumferential) strain values [31]. Moreover, inter- and intraobserver variability of two-dimensional strain echocardiography are better than tissue Doppler values [32].

Myocardial strain can detect subclinical organ damage earlier than other conventional echocardiographic parameters. Kang et al. [33] reported longitudinal strain was decreased in hypertensive patients with normal LV systolic function, and it was correlated with serum level of tissue inhibitor of matrix metalloproteinase-1 level, a marker of myocardial fibrosis.

Three-dimensional strain echocardiography has been developed by technological advancement, and it can track the motion of myocardial speckles stereoscopically [34]. Analysis of the whole LV from a single volume data is the main advantage of three-dimensional strain echocardiography (Figure 5). It can measure longitudinal, circumferential, radial, and area strain and can also reduce the time duration required for analysis [35]. Circumferential strain by three-dimensional echocardiography showed better correlation with LVEF than with global longitudinal strain and radial strain, especially in patients with preserved LV function [36]. Recent studies reported that global area strain is the most reliable surrogate of LVEF [37,38]. Global area strain by three-dimensional strain echocardiography was precociously decreased in hypertensive patients with normal LV systolic function [39]. Three-dimensional echocardiographic strain analysis also can measure regional myocardial function.

\section{Left ventricular diastolic function}

Diastole is a period to fill the LV, and normal diastolic function is required to fill the cardiac chambers without abnormally elevated pressure [40]. The diastole includes four sub-phases: isovolumetric relaxation, early rapid ventricular filling, diastasis, and atrial contraction. Diastole is not a passive process, and it starts after LV contraction [41]. The ventricular myocardium is compressed and twisted during LV systole. The compressed and twisted myocardium was relaxed and unloads the energy required during diastole. Intra-ventricular pressure drops rapidly during the first isovolumetric relaxation period. This relaxation makes a pressure difference between the LA and ventricle that forced the rapid blood flow through the mitral valve and fills the LV rapidly. During diastasis, blood flow continues through the mitral valve. The atrial contraction is the last phase of the diastole, and blood is pumped by the muscular contraction of the atrium.

Although LV diastolic dysfunction is associated with increased mortality in middle-aged and elderly adults [42], the estimation of LV diastolic function is more difficult than the measurement of systolic function [43]. A comprehensive assessment of LV diastolic function should estimate LV filling pressure.

Echocardiography is a useful imaging tool to measure LV diastolic function. Several echocardiographic modalities can be used to estimate LV filling pressure. Increased LA size and volume is one of indicator of increased LV filling pressure [44,45]. Enlarged LA diameter was found more than $20 \%$ of hypertensive patients in a large-scale study including a total of 2,500 uncomplicated essential hypertensives [46]. Enlarged LA can present long-standing elevated LV filling pressure, and increased LA size and volume were associated with poor long-term mortality and morbidity $[47,48]$.

Mitral inflow pattern by pulsed-wave Doppler technique is another maker of diastolic function (Figure 6A). Isovolumic relaxation time, ratio of $\mathrm{E}$ and $\mathrm{A}$ velocities, deceleration time of $\mathrm{E}$ velocity, and duration of $\mathrm{A}$ wave can be used to assess diastolic dysfunction [49]. However, these velocities can be influenced by multiple factors including age, heart rate and rhythm, cardiac output, mitral annular size, and LA function [49].

Mitral annular velocity can be assessed by pulsed-wave Doppler of mitral annulus from tissue Doppler imaging (Figure 6B). Because e' velocity measured by tissue Doppler imaging is inversely proportionate to the relaxation 


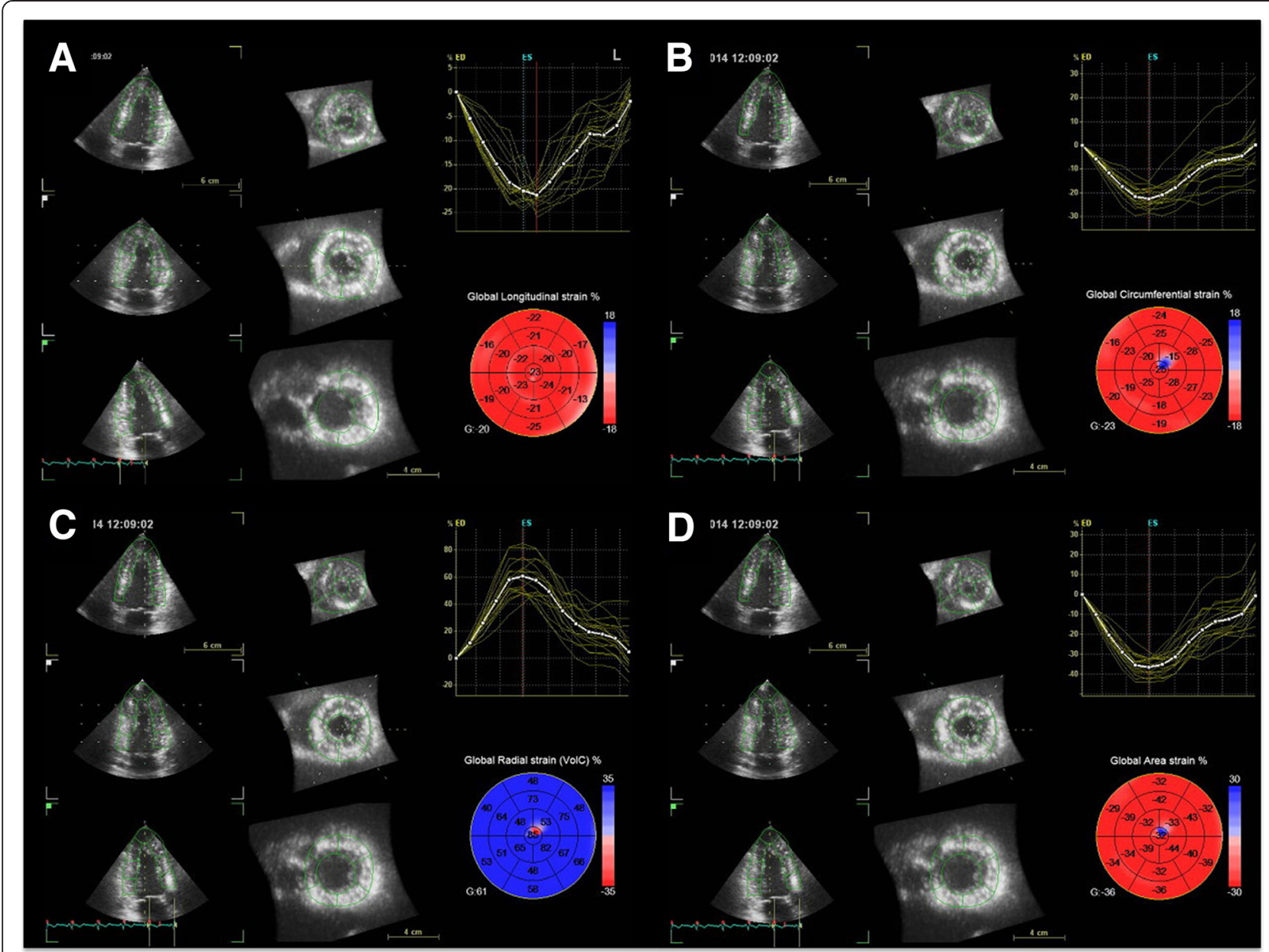

Figure 5 Multiplanar reconstruction images are obtained automatically from single volumetric echocardiographic data. Global longitudinal (A), circumferential (B), radial (C), and area strains (D) can be measured as well as regional segmental values at one analysis.

time constant (tau) only, whereas transmitral E velocity is proportionate to the ratio between LA pressure and tau, the ratio E/e' can be a good indicator of LA pressure [50-52], and it is generally the most feasible marker for estimation of LA filling pressure. Several validation studies have showed good correlation of this ratio with LA filling pressure, and the prediction of normal filling pressure is most reliable when the ratio is $<8$. When the ratio is $>15$, it is an indicator of increased LA filling pressure $[49,52]$.

However, the E/e' ratio has pitfalls in the assessment of LA filling pressure [53]. The E/e' ratio had a poor correlation with LA pressures in patients with advanced systolic heart failure [54]. Situations where the use of E/e' may be unreliable in tachycardia with fusion of mitral $E$ and A velocities, significant valvular heart disease (significant mitral regurgitation, significant mitral stenosis, and aortic regurgitation), and presence of left bundle branch block [53].

Diastolic stress echocardiography using exercise stress can detect hemodynamic consequences of exercise-induced increase in diastolic filling pressure noninvasively [55]. It can detect subclinical diastolic dysfunction and can be valuable in patients with unexplained dyspnea [55].

\section{Left atrial size and function}

LA enlargement is commonly associated with systemic arterial hypertension in patients without significant valvular heart disease, and it is associated with overweight, LVH, and metabolic syndrome [46]. LA size can be calculated with parasternal long-axis view at end systole along its greatest dimension, trying to avoid foreshortening it. Normal LA diameter is $2.7 \sim 3.8 \mathrm{~cm}$ for female and $3.0 \sim$ $4.0 \mathrm{~cm}$ for male [10].

LA volume can be assessed by two-dimensional echocardiography (Figure 7). Normal LA volume is lower than $28 \mathrm{ml} / \mathrm{m}^{2}$ [10], and enlarged LA is one of the poor prognostic markers. Increased LA size and volume can reflect the diastolic dysfunction in hypertensive patients and can be used as one of indicators of cardiovascular morbidity and mortality [45]. Volume more than $34 \mathrm{ml} / \mathrm{m}^{2}$ is associated 


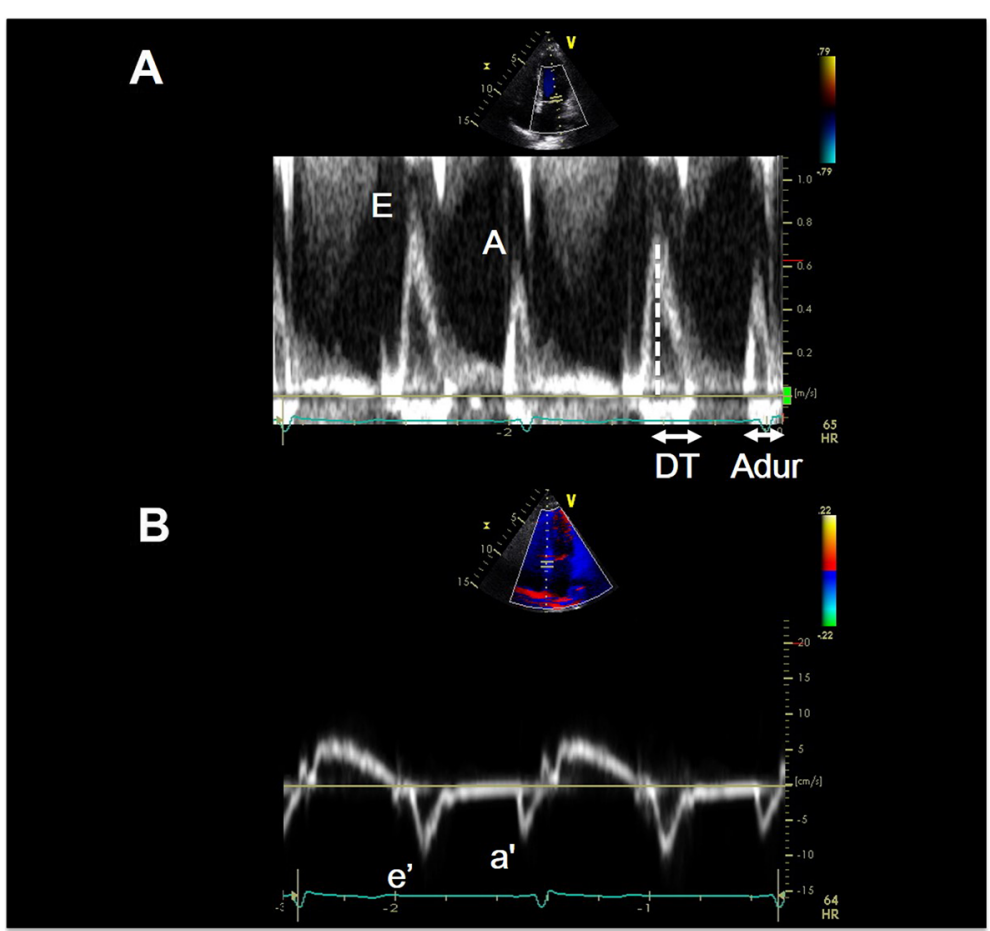

Figure 6 Left ventricular diastolic function can be assessed with mitral inflow velocity and mitral annular velocity. Mitral inflow velocities obtained by pulsed-wave Doppler technique (A) and their schematic diagram. Peak mitral inflow velocity during early diastole (E wave), peak mitral inflow velocity at atrial contraction (A wave), mitral deceleration time (DT), duration of A wave (Adur). Mitral annular velocities obtained by tissue Doppler echocardiography with e' velocity as the early diastolic velocity and a' velocity as the late diastolic velocity (B).

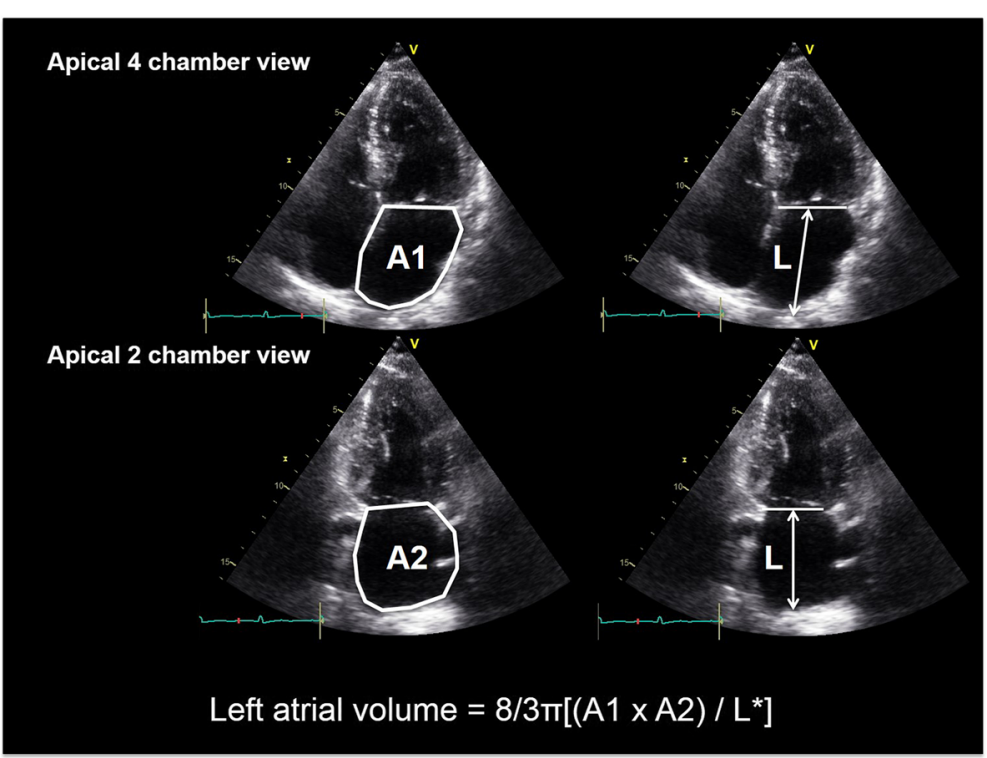

Figure 7 Measurement of left atrial volume from area-length method using apical 4 chamber (A1) and apical 2 chamber (A2) views at ventricular end systole. $L^{*}$ is the shortest of either the apical 4 chamber or apical 2 chamber length. 
with poor prognosis including death, heart failure, atrial fibrillation, and ischemic stroke [56,57]. Because the LA does not show rapid reverse remodeling with treatment, its size or volume is an inadequate marker of therapeutic response.

LA function is important in the regulation of LV filling by reservoir, conduit, and booster pump functions [58]. LA reservoir and conduit functions are essential during the early diastolic phase, and booster pump function is needed in active filling of the LV during the late diastolic phase. The echocardiographic assessment of LA function is relatively difficult due to its anatomical shape [59]. Tissue Doppler imaging has been introduced to measure LA booster function. The positive wave during systole (SRs) reflects the reservoir function, the negative wave during early diastole (SRe) indicates the conduit function, and the negative wave during late diastole (SRa) represents the booster pump function [60,61]. LA strain and strain rate can detect subclinical atrial dysfunction in patients with hypertension [61]. However, strain and strain rate assessed by tissue Doppler imaging have limitation about angle dependency, and the deformation characteristics of the LA in hypertensive patients are still controversial [62].

Two-dimensional speckle-tracking echocardiography has been used in the assessment of LA function in a noninvasive, simple, and reproducible manner [63]. Hypertensive patients with decreased LA function assessed by speckletracking echocardiography have poor prognosis $[64,65]$. Also, strain and strain rate from two-dimensional speckletracking echocardiography may reflect decreased LA conduit function and increased booster pump function in hypertensive patients with LVH [63].

Analysis of LA appendage can give indirect information about LA function, and impaired LA appendageal function in patients with non-dipper compared to dipper hypertensive patients [66]. Although the strain measurement of LA is not recommended in routine clinical practices, it can be a good indicator of LA function.

Three-dimensional echocardiography has been introduced in the measurement of LA size and volume, and it gives many advantages over two-dimensional echocardiography [67]. Real-time three-dimensional echocardiography can provide a reproducible assessment and passive LA function by volumetric cyclic changes [68]. Its measurement of LA volume showed well correlation with LA volume by multi-detector computerized tomography [69]. It may be superior to the two-dimensional echocardiography because of its higher sensitivity to volume changes [68].

\section{Other echocardiographic findings in hypertensive patients}

Secondary pulmonary hypertension can be resulted from increased LA pressure transmitted to pulmonary circulation. Also, HF with preserved ejection fraction is a common cause of pulmonary hypertension [70]. Echocardiography can estimate pulmonary arterial pressure with tricuspid regurgitation velocity or right ventricular outflow track flow profile [71]. Pulmonary arterial systolic pressure can be assessed by adding pressure gradient through right heart chambers (calculated with the Bernoulli equation) to right atrial pressure [72].

$$
\mathrm{PASP}=\mathrm{RVSP}=\mathrm{RAP}+4 \times \mathrm{TRVmax}^{2}
$$

Where PASP is the pulmonary artery systolic pressure, RVSP is the right ventricular systolic pressure, TR Vmax is the maximal tricuspid regurgitant velocity, and RAP is the right atrial pressure.

Right ventricular outflow tract acceleration time is the time from the beginning of the right ventricular ejection until the maximum of the systolic velocity [73]. This acceleration time is about $140 \mathrm{~ms}$ in normal people, and it shortens in patients with pulmonary hypertension (about $80 \mathrm{~ms}$ ).

Because systemic arterial hypertension is also a risk factor of atherosclerosis, atherosclerotic heart diseases can be seen during echocardiographic examination. Ischemic heart disease, dilatation of ascending aorta, and aortic valve sclerosis or stenosis can be found. Presence of regional wall motion abnormalities or ventricular aneurysm is associated with ischemic coronary artery diseases. Stress echocardiography with using exercise protocol or dobutamine stress can detect ischemic heart diseases more sensitively. Dilatation of ascending aorta is associated with increased arterial stiffness and LV mass, and its reported incidence was $17 \%$ in hypertensive patients [74]. Calcific aortic valve diseases are usual manifestations of atherosclerosis. The presence of aortic valve sclerosis is associated with poor clinical outcomes $[75,76]$.

\section{Conclusion}

Because echocardiography can detect cardiac morphologic and hemodynamic change caused by systemic arterial hypertension, echocardiography is a powerful tool for the evaluation of target organ damage, which is essential for the evaluation of cardiovascular risk. Although echocardiography is not an essential first-line imaging study, echocardiography is an excellent tool for the assessment of future cardiovascular risks. Because of its non-invasiveness and easy accessibility, it is also a widely and most commonly used imaging modality in the cardiology practice. However, conventional echocardiography has many pitfalls in the interpretation of several echocardiographic parameters. To overcome this limitation, physicians should be aware of the pitfalls of conventional echocardiographic parameters. Second, doctors should analyze and interpret echocardiographic findings in conjunction with other findings from physical examination and routine examinations. 
Third, it is worthwhile for medical practitioners to learn other newer echocardiographc modalities. Aside from conventional echocardiographic modalities, newer echocardiographic methods including tissue Doppler imaging, strain echocardiography, or three-dimensional echocardiography also have been introduced to evaluate hypertensive patients providing valuable information about the extent of cardiac damages thus helping us to give better treatment.

\section{Abbreviations}

LV: left ventricle; LA: left atrium; LVID: left ventricular internal dimension; IVS: interventricular septum; LVPW: left ventricular posterior wall; LVH: left ventricular hypertrophy; LVEF: left ventricular ejection fraction.

\section{Competing interests}

The authors declare that they have no competing interests.

\section{Authors' contributions}

LH summarized the data and the wrote manuscript, and PJH wrote and reviewed the manuscript. Both authors read and approved the final manuscript.

\section{Acknowledgements}

This work was supported by research fund of Chungnam National University.

Received: 23 December 2014 Accepted: 13 February 2015 Published online: 17 June 2015

\section{References}

1. Staessen JA, Wang J, Bianchi G, Birkenhager WH. Essential hypertension. Lancet. 2003;361:1629-41.

2. Maatouk I, Wild B, Herzog W, Wesche D, Schellberg D, Schottker B, et al. Longitudinal predictors of health-related quality of life in middle-aged and older adults with hypertension: results of a population-based study. J Hypertens. 2012;30:1364-72.

3. Mancia G, Fagard R, Narkiewicz K, Redon J, Zanchetti A, Böhm M, et al. 2013 ESH/ESC guidelines for the management of arterial hypertension: the Task Force for the Management of Arterial Hypertension of the European Society of Hypertension (ESH) and of the European Society of Cardiology (ESC). Eur Heart J. 2013;34:2159-219.

4. Dasgupta K, Quinn RR, Zarnke KB, Rabi DM, Ravani P, Daskalopoulou SS, et al. Canadian Hypertension Education P. The 2014 Canadian hypertension education program recommendations for blood pressure measurement, diagnosis, assessment of risk, prevention, and treatment of hypertension. Can J Cardiol. 2014;30:485-501.

5. James PA, Oparil S, Carter BL, Cushman WC, Dennison-Himmelfarb C, Handler J, et al. 2014 evidence-based guideline for the management of high blood pressure in adults: Report from the panel members appointed to the eighth joint national committee (JNC 8). JAMA. 2014;311:507-20.

6. Chobanian AV, Bakris GL, Black HR, Cushman WC, Green LA, Izzo Jr JL, et al. Treatment of High Blood P, National High Blood Pressure Education Program Coordinating $\mathrm{C}$. The seventh report of the joint national committee on prevention, detection, evaluation, and treatment of high blood pressure: The JNC 7 report. JAMA. 2003;289:2560-72.

7. American College of Cardiology Foundation Appropriate Use Criteria Task F, American Society of E, American Heart A, American Society of Nuclear C, Heart Failure Society of A, Heart Rhythm S, Society for Cardiovascular A, Interventions, Society of Critical Care M, Society of Cardiovascular Computed T, Society for Cardiovascular Magnetic R, American College of Chest P, Douglas PS, Garcia MJ, Haines DE, Lai WW, Manning WJ, et al. Accf/ase/aha/asnc/hfsa/hrs/ $\mathrm{scai} / \mathrm{sccm} / \mathrm{scct} / \mathrm{scmr} 2011$ appropriate use criteria for echocardiography. A report of the american college of cardiology foundation appropriate use criteria task force, american society of echocardiography, american heart association, american society of nuclear cardiology, heart failure society of america, heart rhythm society, society for cardiovascular angiography and interventions, society of critical care medicine, society of cardiovascular computed tomography, society for cardiovascular magnetic resonance american college of chest physicians. J Am Soc Echocardiogr. 2011;24:229-67.
8. Levy D, Garrison RJ, Savage DD, Kannel WB, Castelli WP. Prognostic implications of echocardiographically determined left ventricular mass in the Framingham heart study. N Engl J Med. 1990;322:1561-6.

9. Cuspidi C, Ambrosioni E, Mancia G, Pessina AC, Trimarco B, Zanchetti A, et al. Role of echocardiography and carotid ultrasonography in stratifying risk in patients with essential hypertension: the assessment of prognostic risk observational survey. J Hypertens. 2002;20:1307-14.

10. Lang RM, Bierig M, Devereux RB, Flachskampf FA, Foster E, Pellikka PA, et al. Chamber Quantification Writing G, American Society of Echocardiography's G, Standards C, European Association of E. Recommendations for chamber quantification: A report from the American Society of Echocardiography's guidelines and standards committee and the chamber quantification writing group, developed in conjunction with the european association of echocardiography, a branch of the european society of cardiology. J Am Soc Echocardiogr. 2005;18:1440-63.

11. Devereux RB, Alonso DR, Lutas EM, Gottlieb GJ, Campo E, Sachs I, et al. Echocardiographic assessment of left ventricular hypertrophy: comparison to necropsy findings. Am J Cardiol. 1986;57:450-8.

12. Ganau A, Devereux RB, Roman MJ, de Simone G, Pickering TG, Saba PS, et al. Patterns of left ventricular hypertrophy and geometric remodeling in essential hypertension. J Am Coll Cardiol. 1992;19:1550-8.

13. Krumholz HM, Larson M, Levy D. Prognosis of left ventricular geometric patterns in the Framingham heart study. J Am Coll Cardiol. 1995;25:879-84

14. Ghali JK, Liao Y, Cooper RS. Influence of left ventricular geometric patterns on prognosis in patients with or without coronary artery disease. J Am Coll Cardiol. 1998;31:1635-40.

15. Jung HO, Sheehan FH, Bolson EL, Waiss MP, Otto CM. Evaluation of midwall systolic function in left ventricular hypertrophy: a comparison of 3-dimensional versus 2-dimensional echocardiographic indices. J Am Soc Echocardiogr. 2006;19:802-10.

16. Takeuchi M, Nishikage T, Mor-Avi V, Sugeng L, Weinert L, Nakai H, et al. Measurement of left ventricular mass by real-time three-dimensional echocardiography: validation against magnetic resonance and comparison with two-dimensional and m-mode measurements. J Am Soc Echocardiogr. 2008:21:1001-5.

17. Aurigemma GP, Gottdiener JS, Shemanski L, Gardin J, Kitzman D. Predictive value of systolic and diastolic function for incident congestive heart failure in the elderly: the cardiovascular health study. J Am Coll Cardiol. 2001:37:1042-8.

18. Parisi AF, Moynihan PF, Feldman CL, Folland ED. Approaches to determination of left ventricular volume and ejection fraction by real-time two-dimensional echocardiography. Clin Cardiol. 1979;2:257-63.

19. Gopal AS, Keller AM, Rigling R, King Jr DL, King DL. Left ventricular volume and endocardial surface area by three-dimensional echocardiography: comparison with two-dimensional echocardiography and nuclear magnetic resonance imaging in normal subjects. J Am Coll Cardiol. 1993;22:258-70.

20. Handschumacher MD, Lethor JP, Siu SC, Mele D, Rivera JM, Picard MH, et al. A new integrated system for three-dimensional echocardiographic reconstruction: development and validation for ventricular volume with application in human subjects. J Am Coll Cardiol. 1993;21:743-53.

21. Jiang L, de Prada JAV, Handschumacher MD, Vuille C, Guererro JL, Picard $\mathrm{MH}$, et al. Quantitative three-dimensional reconstruction of aneurysmal left ventricles. In vitro and in vivo validation. Circulation. 1995;91:222-30.

22. Jenkins C, Bricknell K, Hanekom L, Marwick TH. Reproducibility and accuracy of echocardiographic measurements of left ventricular parameters using real-time three-dimensional echocardiography. J Am Coll Cardiol. 2004:44:878-86.

23. Kuhl HP, Schreckenberg M, Rulands D, Katoh M, Schafer W, Schummers G, et al. High-resolution transthoracic real-time three-dimensional echocardiography: quantitation of cardiac volumes and function using semi-automatic border detection and comparison with cardiac magnetic resonance imaging. J Am Coll Cardiol. 2004;43:2083-90.

24. Gutierrez-Chico JL, Zamorano JL, Isla L, Orejas M, Almeria C, Rodrigo JL, et al. Comparison of left ventricular volumes and ejection fractions measured by three-dimensional echocardiography versus by two-dimensional echocardiography and cardiac magnetic resonance in patients with various cardiomyopathies. Am J Cardiol. 2005;95:809-13.

25. Triantafyllou KA, Karabinos E, Kalkandi H, Kranidis Al, Babalis D. Clinical implications of the echocardiographic assessment of left ventricular long axis function. Clin Res Cardiol. 2009;98:521-32. 
26. Koulouris SN, Kostopoulos KG, Triantafyllou KA, Karabinos I, Bouki TP, Karvounis $\mathrm{HI}$, et al. Impaired systolic dysfunction of left ventricular longitudinal fibers: a sign of early hypertensive cardiomyopathy. Clin Cardiol. 2005;28:282-6.

27. Bountioukos M, Schinkel AF, Bax JJ, Lampropoulos S, Poldermans D. The impact of hypertension on systolic and diastolic left ventricular function. A tissue doppler echocardiographic study. Am Heart J. 2006:151:1323 e. 1327-1312.

28. Nishikage T, Nakai H, Lang RM, Takeuchi M. Subclinical left ventricular longitudinal systolic dysfunction in hypertension with no evidence of heart failure. Circ J. 2008;72:189-94.

29. Reisner SA, Lysyansky P, Agmon Y, Mutlak D, Lessick J, Friedman Z. Global longitudinal strain: A novel index of left ventricular systolic function. J Am Soc Echocardiogr. 2004;17:630-3.

30. Leitman M, Lysyansky P, Sidenko S, Shir V, Peleg E, Binenbaum M, et al. Two-dimensional strain-a novel software for real-time quantitative echocardiographic assessment of myocardial function. J Am Soc Echocardiogr. 2004;17:1021-9.

31. Geyer H, Caracciolo G, Abe H, Wilansky S, Carerj S, Gentile F, et al. Assessment of myocardial mechanics using speckle tracking echocardiography: fundamentals and clinical applications. J Am Soc Echocardiogr. 2010;23:351-69. quiz 453-355.

32. Oxborough D, Batterham AM, Shave R, Artis N, Birch KM, Whyte G, et al. Interpretation of two-dimensional and tissue doppler-derived strain (epsilon) and strain rate data: is there a need to normalize for individual variability in left ventricular morphology? Eur J Echocardiogr. 2009;10:677-82.

33. Kang SJ, Lim HS, Choi BJ, Choi SY, Hwang GS, Yoon MH, et al. Longitudinal strain and torsion assessed by two-dimensional speckle tracking correlate with the serum level of tissue inhibitor of matrix metalloproteinase-1, a marker of myocardial fibrosis, in patients with hypertension. J Am Soc Echocardiogr. 2008;21:907-11.

34. Mor-Avi V, Lang RM, Badano LP, Belohlavek M, Cardim NM, Derumeaux G, et al. Current and evolving echocardiographic techniques for the quantitative evaluation of cardiac mechanics: ase/eae consensus statement on methodology and indications endorsed by the Japanese society of echocardiography. Eur J Echocardiogr. 2011;12:167-205.

35. Perez de Isla L, Balcones DV, Fernandez-Golfin C, Marcos-Alberca P, Almeria C, Rodrigo JL, et al. Three-dimensional-wall motion tracking: A new and faster tool for myocardial strain assessment: comparison with two-dimensional-wall motion tracking. J Am Soc Echocardiogr. 2009;22:325-30.

36. Ishizu T, Seo Y, Kameda Y, Kawamura R, Kimura T, Shimojo N, et al. Left ventricular strain and transmural distribution of structural remodeling in hypertensive heart disease. Hypertension. 2014;63:500-6.

37. Wen $H$, Liang Z, Zhao Y, Yang K. Feasibility of detecting early left ventricular systolic dysfunction using global area strain: a novel index derived from threedimensional speckle-tracking echocardiography. Eur J Echocardiogr. 2011;12:910-6.

38. Kleijn SA, Aly MF, Terwee CB, van Rossum AC, Kamp O. Three-dimensional speckle tracking echocardiography for automatic assessment of global and regional left ventricular function based on area strain. J Am Soc Echocardiogr. 2011;24:314-21.

39. Galderisi M, Esposito R, Schiano-Lomoriello V, Santoro A, Ippolito R, Schiattarella $P$, et al. Correlates of global area strain in native hypertensive patients: a threedimensional speckle-tracking echocardiography study. European Heart J Cardiovasc Imaging. 2012;13:730-8.

40. Cheng CP, Noda T, Nozawa T, Little WC. Effect of heart failure on the mechanism of exercise-induced augmentation of mitral valve flow. Circ Res. 1993;72:795-806

41. Little WC. Diastolic dysfunction beyond distensibility: adverse effects of ventricular dilatation. Circulation. 2005;112:2888-90.

42. Bella JN, Palmieri V, Roman MJ, Liu JE, Welty TK, Lee ET, et al. Mitral ratio of peak early to late diastolic filling velocity as a predictor of mortality in middle-aged and elderly adults: the strong heart study. Circulation. 2002;105:1928-33.

43. How to diagnose diastolic heart failure. European study group on diastolic heart failure. Eur Heart J. 1998;19(7):990-1003.

44. Appleton CP, Galloway JM, Gonzalez MS, Gaballa M, Basnight MA. Estimation of left ventricular filling pressures using two-dimensional and doppler echocardiography in adult patients with cardiac disease. Additional value of analyzing left atrial size, left atrial ejection fraction and the difference in duration of pulmonary venous and mitral flow velocity at atrial contraction. J Am Coll Cardiol. 1993;22:1972-82.

45. Russo C, Jin Z, Homma S, Rundek T, Elkind MS, Sacco RL, et al. Left atrial minimum volume and reservoir function as correlates of left ventricular diastolic function: impact of left ventricular systolic function. Heart. 2012;98:813-20.

46. Cuspidi C, Meani S, Fusi V, Valerio C, Catini E, Sala C, et al. Prevalence and correlates of left atrial enlargement in essential hypertension: Role of ventricular geometry and the metabolic syndrome: the evaluation of target organ damage in hypertension study. J Hypertens. 2005;23:875-82.

47. Moller JE, Hillis GS, Oh JK, Seward JB, Reeder GS, Wright RS, et al. Left atrial volume: a powerful predictor of survival after acute myocardial infarction. Circulation. 2003;107:2207-12.

48. Wu VC, Takeuchi M, Kuwaki H, Iwataki M, Nagata Y, Otani K, et al. Prognostic value of la volumes assessed by transthoracic 3D echocardiography: comparison with 2D echocardiography. J Am Coll Cardiol Img. 2013;6:1025-35.

49. Nagueh SF, Appleton CP, Gillebert TC, Marino PN, Oh JK, Smiseth OA, et al. Recommendations for the evaluation of left ventricular diastolic function by echocardiography. Eur J Echocardiogr. 2009;10:165-93.

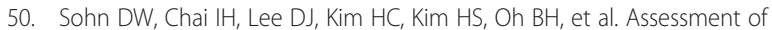
mitral annulus velocity by doppler tissue imaging in the evaluation of left ventricular diastolic function. J Am Coll Cardiol. 1997;30:474-80.

51. Ommen SR, Nishimura RA, Appleton CP, Miller FA, Oh JK, Redfield MM, et al. Clinical utility of doppler echocardiography and tissue doppler imaging in the estimation of left ventricular filling pressures: a comparative simultaneous doppler-catheterization study. Circulation. 2000;102:1788-94.

52. Nagueh SF, Mikati I, Kopelen HA, Middleton KJ, Quinones MA, Zoghbi WA. Doppler estimation of left ventricular filling pressure in sinus tachycardia. A new application of tissue doppler imaging. Circulation. 1998;98:1644-50.

53. Park JH, Marwick TH. Use and limitations of e/e' to assess left ventricular filling pressure by echocardiography. J Cardiovasc Ultrasound. 2011;19:169-73.

54. Mullens W, Borowski AG, Curtin RJ, Thomas JD, Tang WH. Tissue doppler imaging in the estimation of intracardiac filling pressure in decompensated patients with advanced systolic heart failure. Circulation. 2009;119:62-70.

55. Ha JW, Oh JK, Pellikka PA, Ommen SR, Stussy VL, Bailey KR, et al. Diastolic stress echocardiography: a novel noninvasive diagnostic test for diastolic dysfunction using supine bicycle exercise doppler echocardiography. J Am Soc Echocardiogr. 2005;18:63-8.

56. Abhayaratna WP, Seward JB, Appleton CP, Douglas PS, Oh JK, Tajik AJ, et al. Left atrial size: physiologic determinants and clinical applications. J Am Coll Cardiol. 2006:47:2357-63.

57. Tsang TS, Barnes ME, Bailey KR, Leibson CL, Montgomery SC, Takemoto Y, et al. Left atrial volume: important risk marker of incident atrial fibrillation in 1655 older men and women. Mayo Clin Proc. 2001;76:467-75.

58. Blume GG, McLeod CJ, Barnes ME, Seward JB, Pellikka PA, Bastiansen PM, et al. Left atrial function: physiology, assessment, and clinical implications. Eur J Echocardiogr. 2011;12:421-30

59. Khankirawatana B, Khankirawatana S, Porter T. How should left atrial size be reported? Comparative assessment with use of multiple echocardiographic methods. Am Heart J. 2004;147:369-74.

60. Sirbu C, Herbots L, D'Hooge J, Claus P, Marciniak A, Langeland T, et al. Feasibility of strain and strain rate imaging for the assessment of regional left atrial deformation: a study in normal subjects. Eur J Echocardiogr. 2006;7:199-208.

61. Baltabaeva A, Marciniak M, Bijnens B, Parsai C, Moggridge J, Antonios TF, et al. How to detect early left atrial remodelling and dysfunction in mildto-moderate hypertension. J Hypertens. 2009;27:2086-93.

62. Eshoo S, Semsarian C, Ross DL, Marwick TH, Thomas L. Comparison of left atrial phasic function in hypertrophic cardiomyopathy versus systemic hypertension using strain rate imaging. Am J Cardiol. 2011;107:290-6.

63. Yang L, Qiu Q, Fang SH. Evaluation of left atrial function in hypertensive patients with and without left ventricular hypertrophy using velocity vector imaging. Int J Cardiovasc Imaging. 2014;30:1465-71.

64. Miyoshi H, Oishi Y, Mizuguchi Y, luchi A, Nagase N, Ara N, et al. Contribution of obesity to left atrial and left ventricular dysfunction in asymptomatic patients with hypertension: a two-dimensional speckle-tracking echocardiographic study. J Am Soc Hypertens. 2014;8:54-63.

65. Liu Y, Wang K, Su D, Cong T, Cheng Y, Zhang Y, et al. Noninvasive assessment of left atrial phasic function in patients with hypertension and diabetes using two-dimensional speckle tracking and volumetric parameters. Echocardiography. 2014;31:727-35.

66. Kumak F, Gungor H. Comparison of the left atrial appendage flow velocities between patients with dipper versus nondipper hypertension. Echocardiography. 2012;29:391-6. 
67. Jenkins C, Bricknell K, Marwick TH. Use of real-time three-dimensional echocardiography to measure left atrial volume: comparison with other echocardiographic techniques. J Am Soc Echocardiogr. 2005;18:991-7.

68. Anwar AM, Soliman Ol, Geleijnse ML, Nemes A, Vletter WB, ten Cate FJ. Assessment of left atrial volume and function by real-time three-dimensional echocardiography. Int J Cardiol. 2008;123:155-61.

69. Miyasaka Y, Tsujimoto S, Maeba H, Yuasa F, Takehana K, Dote K, et al. Left atrial volume by real-time three-dimensional echocardiography: validation by 64-slice multidetector computed tomography. J Am Soc Echocardiogr. 2011:24:680-6.

70. Thenappan T, Shah SJ, Gomberg-Maitland M, Collander B, Vallakati A, Shroff $P$, et al. Clinical characteristics of pulmonary hypertension in patients with heart failure and preserved ejection fraction. Circ Heart Fail. 2011:4:257-65.

71. Grapsa J, Dawson D, Nihoyannopoulos P. Assessment of right ventricular structure and function in pulmonary hypertension. J Cardiovasc Ultrasound. 2011;19:115-25.

72. Kaul S, Tei C, Hopkins JM, Shah PM. Assessment of right ventricular function using two-dimensional echocardiography. Am Heart J. 1984;107:526-31.

73. Kitabatake A, Inoue M, Asao M, Masuyama T, Tanouchi J, Morita T, et al. Noninvasive evaluation of pulmonary hypertension by a pulsed Doppler technique. Circulation. 1983;68:302-9.

74. Milan A, Tosello F, Naso D, Avenatti E, Leone D, Magnino C, et al. Ascending aortic dilatation, arterial stiffness and cardiac organ damage in essential hypertension. J Hypertens. 2013;31:109-16.

75. Otto CM, Lind BK, Kitzman DW, Gersh BJ, Siscovick DS. Association of aortic-valve sclerosis with cardiovascular mortality and morbidity in the elderly. N Engl J Med. 1999;341:142-7.

76. Volzke H, Haring R, Lorbeer R, Wallaschofski H, Reffelmann T, Empen $K$, et al. Heart valve sclerosis predicts all-cause and cardiovascular mortality. Atherosclerosis. 2010;209:606-10

\section{Submit your next manuscript to BioMed Central and take full advantage of:}

- Convenient online submission

- Thorough peer review

- No space constraints or color figure charges

- Immediate publication on acceptance

- Inclusion in PubMed, CAS, Scopus and Google Scholar

- Research which is freely available for redistribution 